\title{
Swept blade influence on aerodynamic performance of steam turbine nozzle cascades
}

\author{
ZI-MING FENG ${ }^{1, *}$, JINGJING TAN $^{1}$, XIAOLEI LIU ${ }^{2, *}$ and CUI WEI ${ }^{1}$ \\ ${ }^{1}$ School of Mechanical Science and Engineering, Northeast petroleum university, Daqing 163318, China \\ ${ }^{2}$ Oil and Gas Engineering Centre, Cranfield University, MK43 0AL Cranfield, UK \\ e-mail: xueyuanfzm@163.com; 1329331833@qq.com; Xiaolei.Liu@cranfield.ac.uk; 83926003@qq.com
}

MS received 7 June 2016; revised 28 October 2017; accepted 21 January 2018; published online 12 April 2018

\begin{abstract}
To improve the aerodynamic performance of steam turbine nozzle cascades, it is significant to study the effect of swept blades to control the flow field within the cascade. Numerical simulations of three different sweep angle blades $\left(-20^{\circ},+20^{\circ}\right.$ and $\left.0^{\circ}\right)$ were carried out, using CFD modelling. Simulation results showed that the aft-swept blade can effectively improve the corresponding flow characteristics and reduce the total pressure loss. Meanwhile, it has better aerodynamic performance than the straight blade and the fore-swept blade.
\end{abstract}

Keywords. Aft-swept blade; fore-swept blade; aerodynamic performance; nozzle cascades.

\section{Introduction}

Even if the inlet flow of cascade is uniform and stable, the impeller will still develop the periodical pulsing gas flow by itself. The produced pulsing gas flow was made up of various vortex systems, such as the transverse flow at the endwalls, the secondary flow vortex and the leakage vortex in the cascade passage. Recently, the swept blade technology had been widely investigated and applied in the field of turbomachinery. Many scholars had extensively studied the swept blade technology [1-3]. For instance, Sasaki and Breugulmans [4] defined the concept of swept angle and height with two-dimensional coordinates. Based on the differences between the internal flow and the external flow in the public domain [5], the three-dimensional coordinates of sweep angle were defined as: the coangle of the dihedral angle between the local flow velocity vector and the tangent line of blade leading is the swept angle. According to the numerical simulation of Corsini and Rispoli [6], the for-swept blade with an angle of $35^{\circ}$ can reduce the flow loss. Another investigation [7] pointed out that, comparing to the radial straight fan, the efficiency and the stall margin of the forward swept fan increased by $0.4 \%$ and $5-10 \%$, respectively. It shown that the swept blade technology can effectively reduce the flow loss, improve the inner flow efficiency, decrease the aerodynamic noise and expand the stable working condition range.

Although the application of swept blades has been extensively studied on compressors, its utilization on steam turbine still needs to be further researched. Many authors only focused their investigations on the performance of

*For correspondence circumferential skewed blades and tangential skew blades. The aerodynamic numerical simulation of the fore-swept blade, the aft-swept blade and the radial straight blade of turbine stator cascade were conducted in different literatures [8]. The obtained results presented the total pressure loss coefficient (TPC) of $20^{\circ}$ fore-swept blade at the outlet can be decreased by about $54 \%$ than the radial straight blade. In this paper, the high-pressure steam turbine nozzle cascade blade was selected as the prototype that was redesigned into two swept blades with $+20^{\circ}$ and $-20^{\circ}$ angle. The aerodynamic numerical simulation of the prototype blade (straight blade), the aft-swept blade $\left(-20^{\circ}\right.$ swept angle) and the foreswept blade $\left(-20^{\circ}\right.$ swept angle) were carried out by using CFD modelling. The results indicated that the aft-swept blade could effectively improve the aerodynamic performance and reduce the total pressure loss. The overall aerodynamic performance of the aft-swept blade is better than the straight blade and the fore-swept blade.

\section{Computation simulation method}

\subsection{Navier-Stokes equations}

The general Navier-Stokes equations can be written in a Cartesian frame:

$$
\frac{\partial}{\partial t} \int_{\Omega} U d \Omega+\int_{S} \vec{F}_{I} \cdot d \vec{S}+\int_{S} \vec{F}_{V} \cdot d \vec{S}=\int_{\Omega} S_{T} d \Omega
$$

where $\Omega$ is the volume and $S$ is the surface.

$U$ is the vector of conservative variables. 
$\vec{F}_{I}$ and $\vec{F}_{V}$ are the inviscid and the viscous flux vectors, respectively.

$E$ and $q_{i}$ are the total energy and the heat flux components, respectively.

$k$ and $S_{T}$ are the laminar thermal conductivity and the source terms, respectively.

\subsection{Standard $k-\varepsilon$ model}

The standard $k-\varepsilon$ model [9] is a semi-empirical model based on transport equations of the turbulence kinetic energy $(k)$ and its dissipation rate $(\varepsilon)$. The model transport equation of $k$ is derived from the exact equation, while the model transport equation of $\varepsilon$ was obtained using physical reasoning and bears little resemblance to its mathematically exact counterpart.

In the derivation of the $k-\varepsilon$ model, it was assumed that the flow is fully turbulent, and the effects of molecular viscosity are negligible. Therefore, the standard $k-\varepsilon$ model is valid only for fully turbulent flows.

2.2a Transport equation for the standard $k-\varepsilon$ model: The turbulence kinetic energy $k$ and its rate of dissipation $\varepsilon$ are obtained from the following transport equations;

$$
\begin{aligned}
\frac{\partial}{\partial t}(\rho k)+\frac{\partial}{\partial x_{i}}\left(\rho k u_{i}\right)=\frac{\partial}{\partial x_{j}} & {\left[\left(\mu+\frac{\mu_{t}}{\sigma_{k}}\right) \frac{\partial k}{\partial x_{j}}\right] } \\
& +G_{k}+G_{b}-\rho \varepsilon-Y_{M}+S_{k}
\end{aligned}
$$

and

$$
\begin{aligned}
\frac{\partial}{\partial t}(\rho \varepsilon)+\frac{\partial}{\partial x_{i}}\left(\rho \varepsilon u_{i}\right)= & \frac{\partial}{\partial x_{j}}\left[\left(\mu+\frac{\mu_{t}}{\sigma_{\varepsilon}}\right) \frac{\partial \varepsilon}{\partial x_{j}}\right] \\
& +C_{1 \varepsilon} \frac{\varepsilon}{k}\left(G_{k}+C_{3 \varepsilon} G_{b}\right)-C_{2 \varepsilon} \rho \frac{\varepsilon^{2}}{k}+S_{\varepsilon}
\end{aligned}
$$

In these equations, $G_{k}$ represents the generation of turbulence kinetic energy due to the mean velocity gradients. $G_{b}$ is the generation of turbulence kinetic energy due to the buoyancy. $Y_{M}$ representsthe contribution of the fluctuating dilatation in the compressible turbulence of the overall dissipation rate.

$C_{1 \varepsilon}, C_{2 \varepsilon}$, and $C_{3 \varepsilon}$ are constants. $\sigma_{k}$ and $\sigma_{\varepsilon}$ are the turbulent Prandtl numbers of $k$ and $\varepsilon$, respectively. $S_{k}$ and $S_{\varepsilon}$ are user-defined source terms.

2.2b Modeling the turbulent viscosity: The turbulent (or eddy) viscosity $\mu_{t}$ is computed by combining $k$ and $\varepsilon$ as follows:

$$
\mu_{t}=\rho C_{\mu} \frac{k^{2}}{\varepsilon}
$$

where $C_{\mu}$ is constant.

2.2c Model constants: The model constants of $C_{1 \varepsilon}, C_{2 \varepsilon}, C_{\mu}$, $\sigma_{k}$ and $\sigma_{\varepsilon}$ have the following default values: (a)

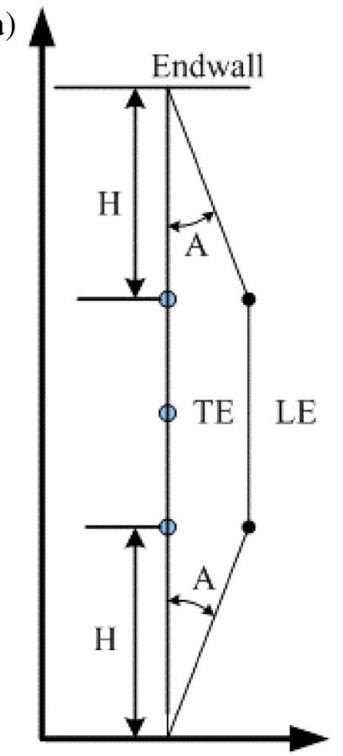

Endwall (b)

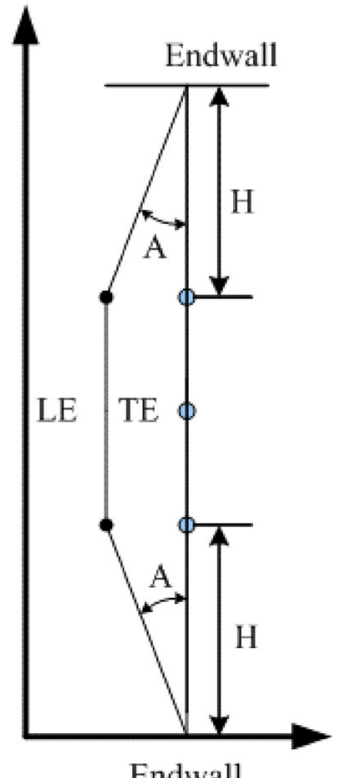

Figure 1. The geometrical type of swept blade: (a) fore-swept blade; (b) aft-swept blade.

$$
C_{1 \varepsilon}=1.44, C_{2 \varepsilon}=1.92, C_{\mu}=0.09, \sigma_{k}=1.0, \sigma_{\varepsilon}=1.3
$$

These default values have been determined from experiments with air and water for fundamental turbulent shear flows, including homogeneous shear flows and decaying isotropic grid turbulence. They worked fairly well for a wide range of wall-bounded and free shear flows.

\subsection{Geometric model 3 of blade}

The steam turbine nozzle blade was selected as the prototype blade. As shown in figure 1, by changing the sweep angle (A) and the sweep height (H), two types of sweep blades were obtained, including one fore-swept blade and one aft-swept blade.

Based on the comparison of the skew direction of coming flow and the leading edge (LE) line of blade,the swept blades can be classified as the fore-swept blade and the aft-swept blade. The fore-swept blade indicated that the LE line was tilted against the direction of coming flow, otherwise it was the aft-swept blade, where the LE line was tilted along the direction of coming flow. The geometric definition of swept angle and height were presented in figure 1 . The TE was the trailing edge. The geometric parameters of the prototype blade are described in the table 1. The fore-swept blade and the aft-swept blade were deformed by using $+20^{\circ},-20^{\circ}$ swept angle, respectively, wherein their sweep heights were $30 \%$ of the blade height.

The basic geometric parameters of prototype blade were shown as in table 1. 
Table 1. Geometry parameters of blade cascades.

\begin{tabular}{lc}
\hline Content & Data \\
\hline Outer, middle and inner diameter $(\mathrm{mm})$ & $1612 ; 1586 ; 1560$ \\
Blade height $(\mathrm{mm})$ & 52 \\
Chord length $(\mathrm{mm})$ & 100 \\
Pitch $(\mathrm{mm})$ & 34.76 \\
Pitch ratio & 0.35 \\
Blade number & 90 \\
Inlet flow angle & $\mathrm{a}_{0}=90^{\circ}$ \\
Outlet flow angle & $\mathrm{a}_{1}=15^{\circ}$ \\
\hline
\end{tabular}

\subsection{Grid mesh and boundary conditions}

In the numerical simulation, the three swept angles were $-20^{\circ},+20^{\circ}$ and $0^{\circ}$, respectively. In each case, the swept height was $30 \%$ of the blade height. The used CFD simulation software was ANSYS-CFX. The mesh grid was generated by using AUTOGRID package. As shown in figure 2, the inlet, the cascade passage and the outlet was structure by H-Grid, O-Grid and I-Grid, respectively, which were created for the computational domain. The grid minimum orthogonality was $37.5^{\circ}$. The maximum ratio of length to width was 262 . The maximum expansion ratio was 2.97 . The total grid nodes were 459500 . The quality of mesh grid meets the requirements of CFX for the computational fluid dynamics.

In this study, the inlet and outlet boundary conditions were the total pressure and the static pressure, respectively. The inlet velocity was uniformed, which will be calculated by the CFX. The outlet boundary condition was the static pressure condition, where a constant value was provided. The boundary conditions of internal aerodynamic simulation were as following:

The inlet total pressure was $0.1031 \mathrm{~Pa}$; the inlet total temperature was $316 \mathrm{~K}$; the outlet pressure was $0.1 \mathrm{MPa}$; the boundary condition of endwalls and lateral walls were no-slip wall and thermal isolation; the turbulence model was the standard $k-\varepsilon$ model.

\section{Results and discussion}

In this section, the aerodynamic performance of the prototype blade, the aft-swept blade and the fore-swept blade were compared with the static pressure distribution along profile of blades, pitch-averaged static pressure isoline distribution, total pressure coefficient at the outlet section and along axial direction.

\subsection{Static pressure coefficient distribution along blade profile}

Figure $3 \mathrm{a}, \mathrm{b}$ and $\mathrm{c}$ depicted the static pressure coefficient (SPC) distribution of the prototype blade, the fore-swept blade and the aft-swept blade along the blade profile, at $10 \%, 50 \%$ and $90 \%$ blade height, respectively.

As shown in figure 3 , at the arbitrary location of the blade height, the lowest pressure points in the suction side of the three blades were all located in the 90-95\% scope of the relatively axial chord lengths. According to the definition of rear-loaded blade, if the lowest pressure point in the suction side was after $60 \%$ relatively axial chord lengths, the blade profile is called aft-loading blade. Obviously, the prototype blade, the fore-swept blade and the aft-swept blade in this work are all aft-loading blades. As for the aftloading blade, in the blade pressure side and most of the suction side $(0-95 \%)$, the boundary layer flow is accelerated under the accelerating pressure gradient, and the boundary layer thickness increased slowly. When the suction side boundary layer with a certain thickness encountered the adverse pressure gradient in the trailing edge, the stream flow may have already entered into the downstream

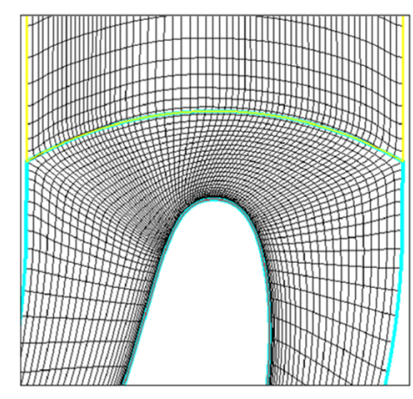

(a)

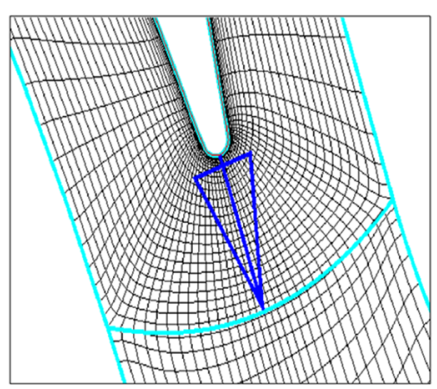

(b)

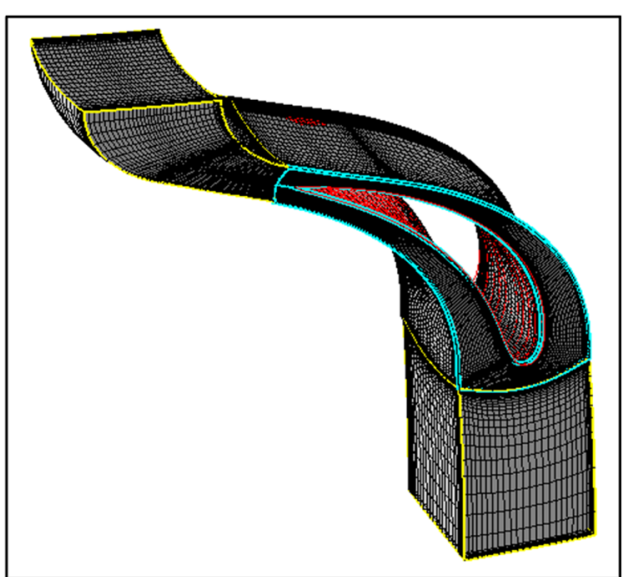

(c)

Figure 2. Computation grid: (a) grid of leading edge part; (b) grid of trailing edge part; (c) 3D grids. 

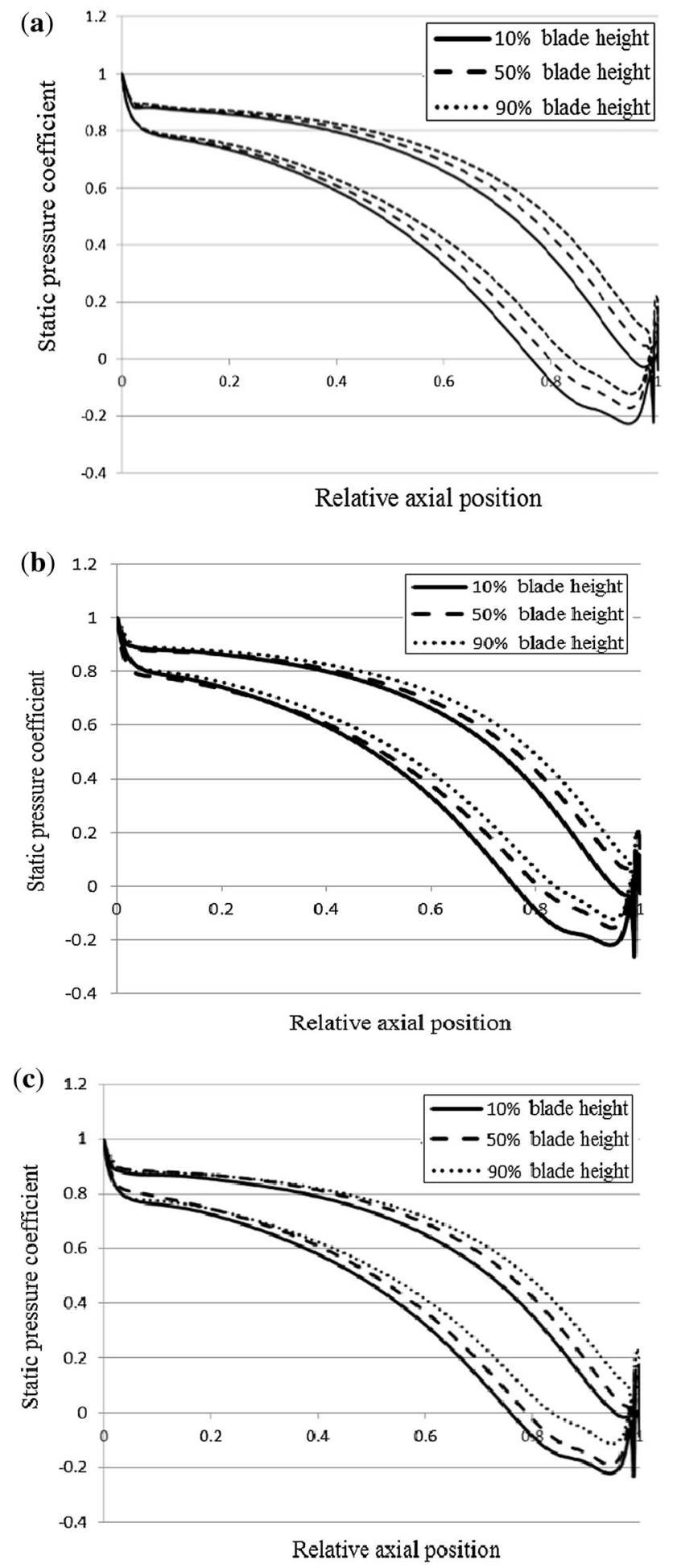

Figure 3. SPC distribution along blade profile at different blade height: (a) prototype blade; (b) fore-swept blade; (c) aft-swept blade.

flow field before the turbulent transition. Therefore, the boundary layer on the aft-loading blade surface has smaller zone with curved streamlines near the tailing of blade.

\subsection{SPC isoline distribution on blade surface}

As shown in figure 4 , for the prototype blade cascade, the static pressure isoline is substantially perpendicular to the endwalls, and the static pressure field substantially presents two-dimensional characteristic, which is the laminar region. When the stream flow entered into the adverse pressure gradient section, the static pressure isoline is closed,which indicates this section is a three-dimensional flow region and also a high loss region.

The fore-swept blade significantly changes the distribution of static pressure isoline, causes the bending of the static pressure isoline in a wide range of meridian plane and forms the positive pressure gradient from the blade root to the blade middle. At the most axial position along spanwise, the static pressure is reverse C-type distribution.

Along the axial direction, static pressure isoline is gradually intensive, and the pressure gradient increases, which will influence the development of the boundary layer. The reverse C-type SPC distribution shows that the static pressure is small at the upper and lower endwall and is high in the main area of middle blade. This static pressure distribution will push the middle blade boundary layer with low energy towards both endwalls. The low energy fluid is gathered on both endwalls, thus the boundary layer thickness is increased on both endwalls. With the endwalls flow decreasing, the boundary layer loss in the middle blade is decreased, but the loss reduction is not enough to compensate the increased loss at both endwalls. Therefore, in general, the fore-swept blade cascades will increase the flow loss.

As to the aft-swept blade cascades, the static pressure isoline is bent, and the bent direction is opposite to the foreswept. The static pressure isoline curves are all C-type distribution along spanwise at most meridian surface. The C-type distribution of SPC shows that the blade pressure distribution is bigger at hub and casing endwalls than the main area of the middle blade. The main stream flow in the middle blade entrains the low-energy boundary layers from the hub and the casing endwalls to make the corner flow smooth, which weakens the loss of the secondary flow of the two endwalls. But the main stream flow increases the loss of the boundary layer of the middle blade. In general, the flow loss decreases because of the aft-swept blade's controlling action. The aft-swept blade has better flow properties in the whole flow passage than the other two blades.

\subsection{Pitch-averaged TPC distribution at outlet section}

Figure 5 shown the total pressure coefficient (TPC) isoline distribution on the outlet cross-section surface of the three blades. In the three types of blades, the high loss regions are all located in the upper endwalls, the lower endwalls and the wake region. 
(a)

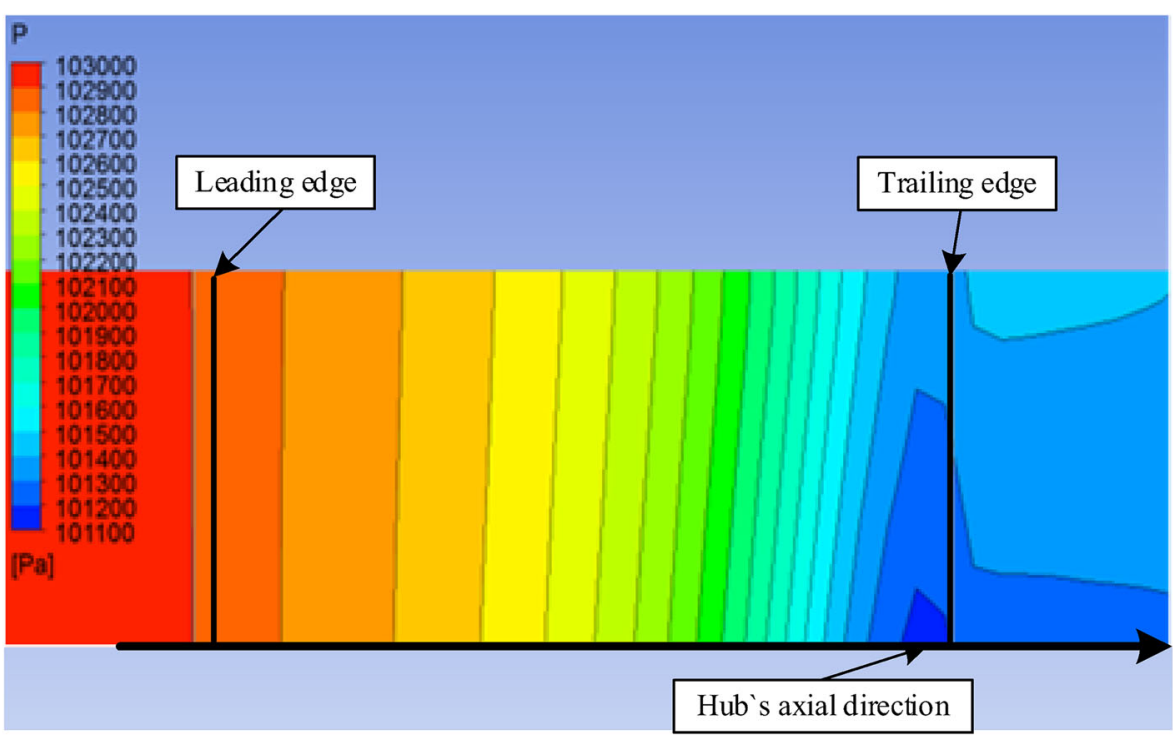

(b)

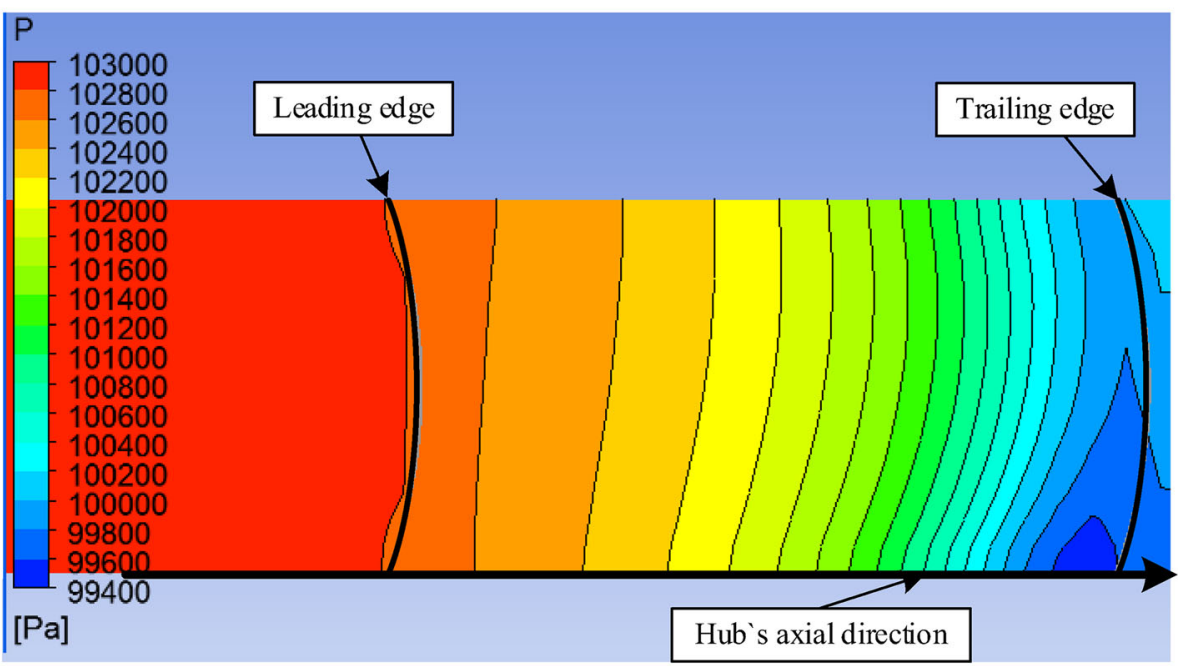

(c)

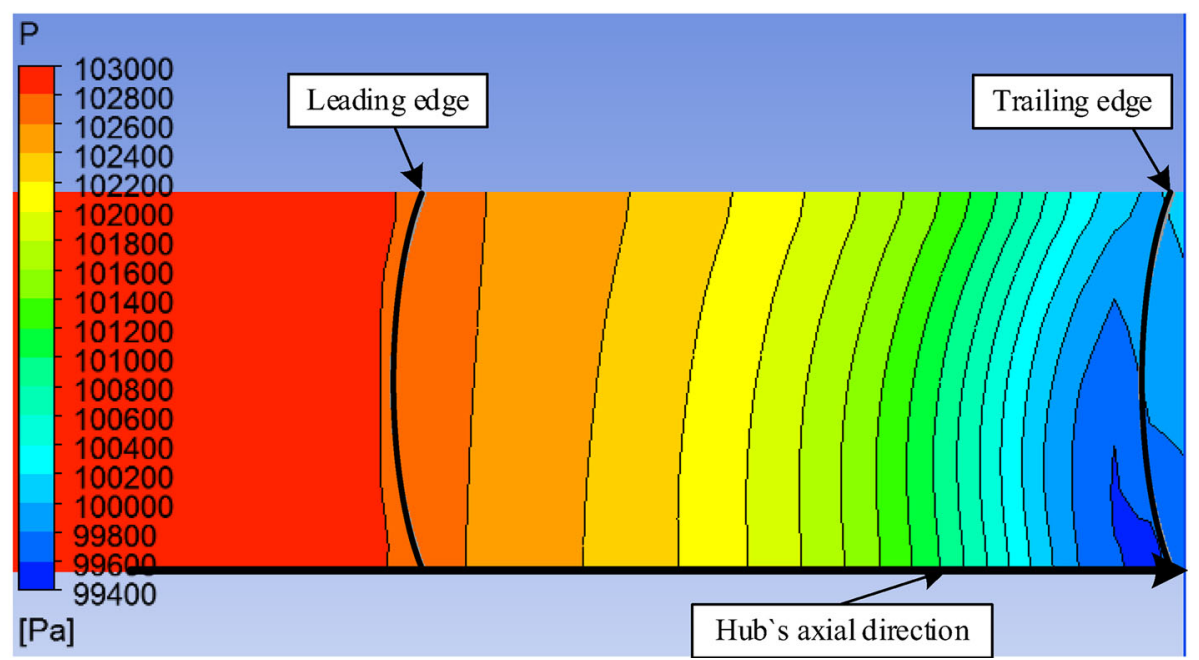

Figure 4. Pitch-averaged SPC isoline distribution: (a) prototype blade; (b) fore-swept blade; (c) aft-swept blade.

In the flow passages of cascade, a reverse C-type and a C-type static pressure distribution along spanwise are formed by the fore-swept blade and the aft-swept blade, respectively.
Under the influence of two static pressure distribution, two vortex losses cores induced by up and down passage vortex departs and moves towards the middle of blade, respectively. 
(a)

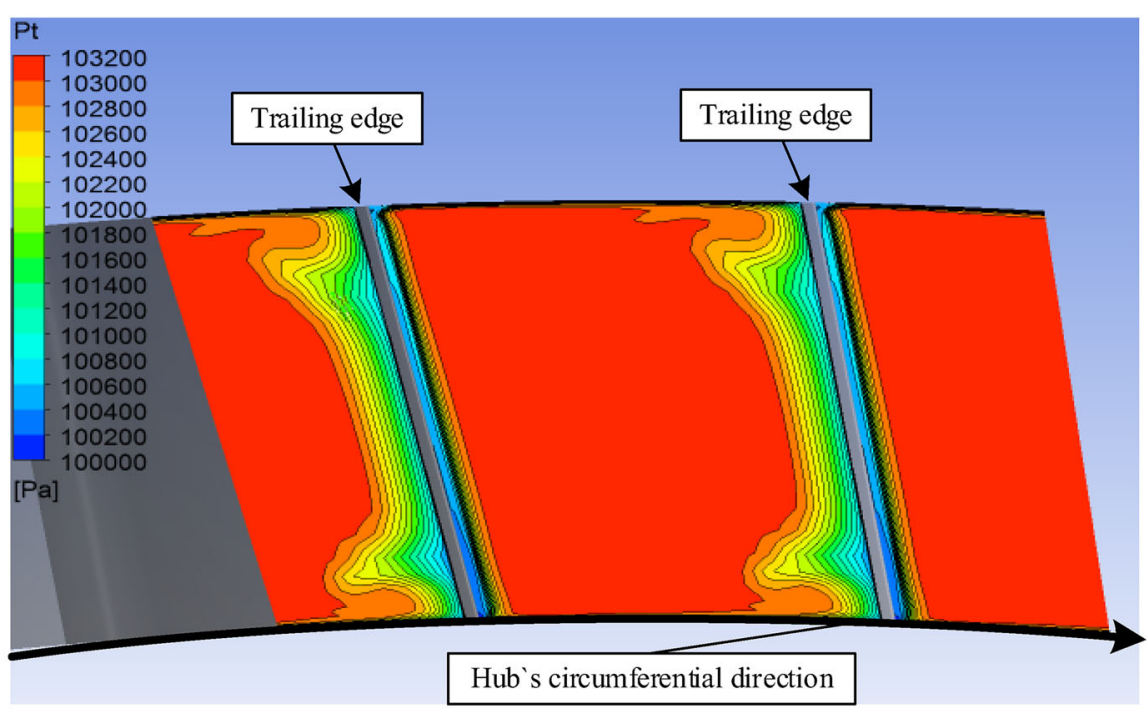

(b)

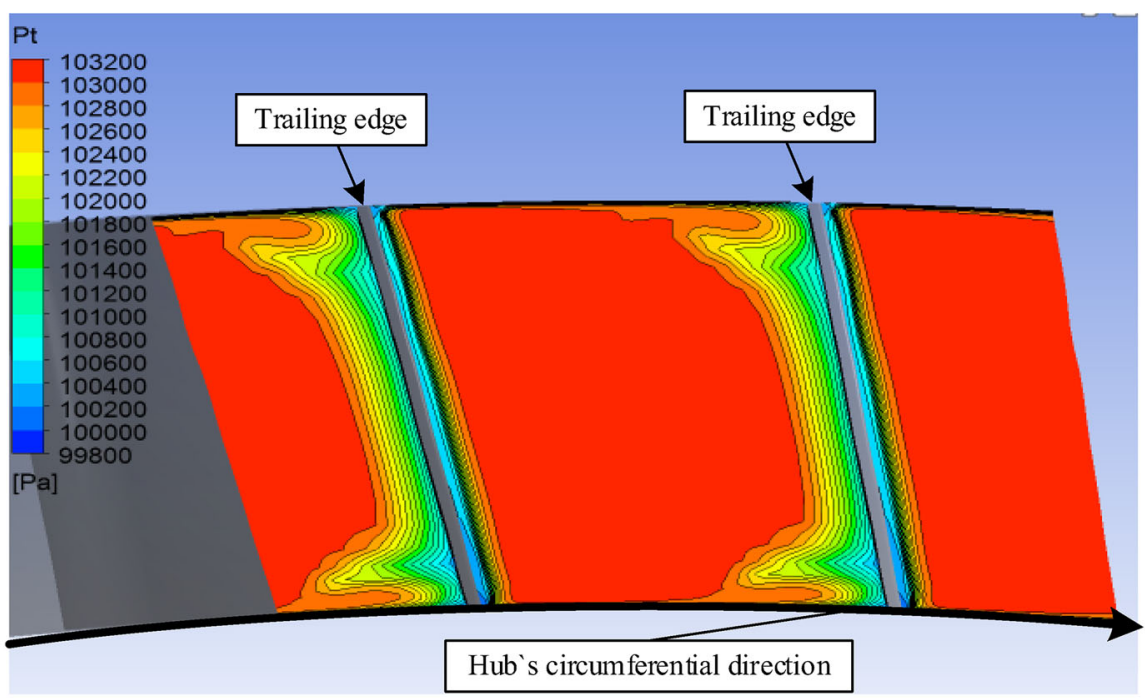

(c) $\mathrm{PI}$

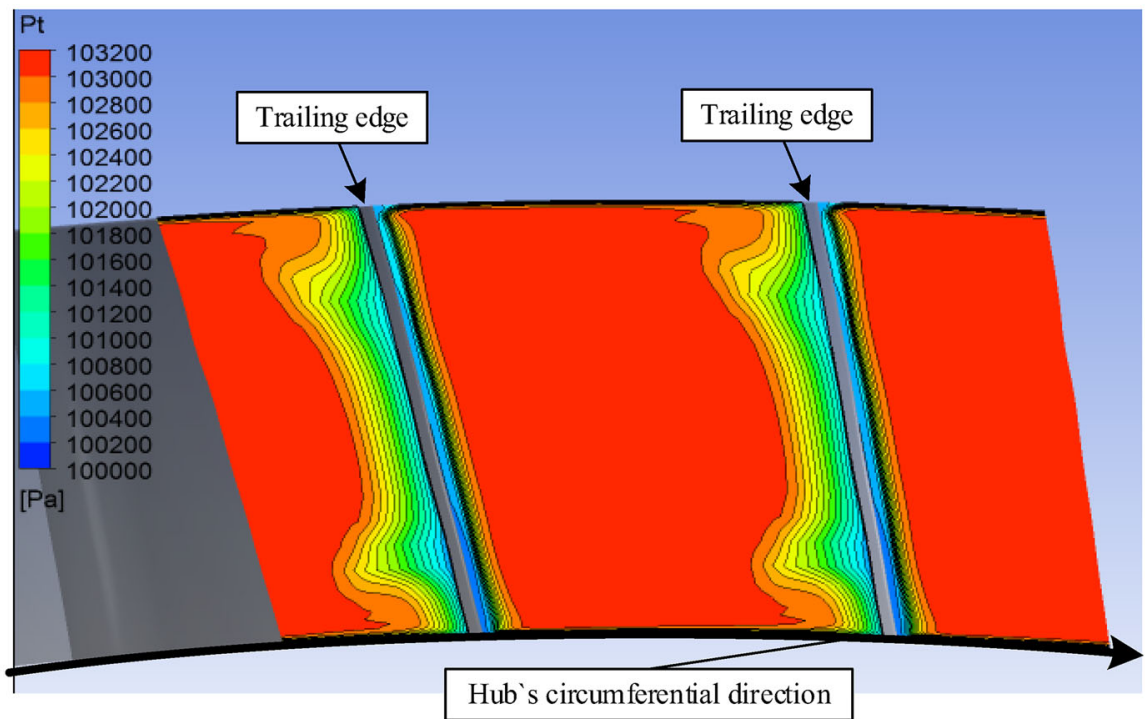

Figure 5. TPC isoline distribution on cross section at outlet: (a) prototype blade; (b) fore-swept blade; (c) aft-swept blade. 


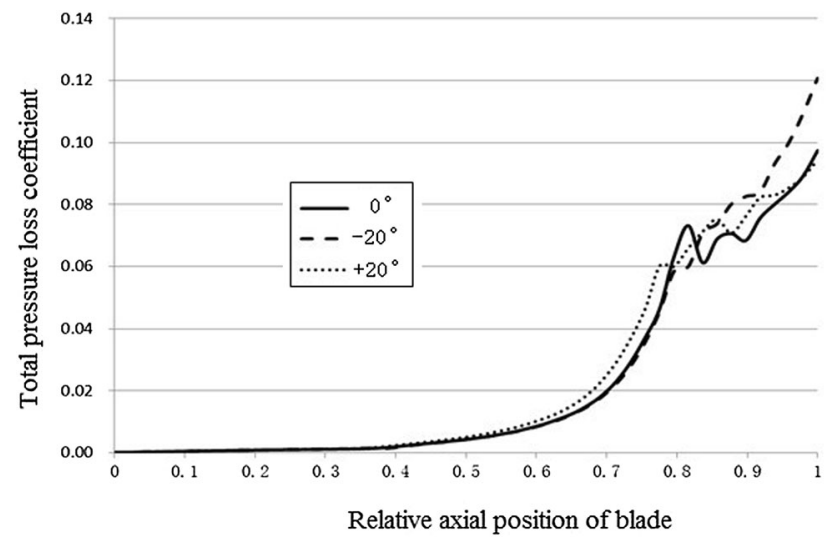

Figure 6. TPC distribution along axial direction.

Comparing with two loss cores of the straight blade, the loss of aft-swept blade is smaller than the straight blade and the fore-swept blade. Furthermore, the loss of fore-swept blade is bigger than the straight blade and the aft-swept blade. It is obvious that the high loss area of the fore-swept cascades is bigger than the aft-swept cascades.

For the aft-swept cascades, the upper and the lower passage vortex loss cores are further away from the upper and lower endwalls of the outlet. On the other hand, its waking area are much narrower than the other two types of cascades, especially in the middle of spanwise. The reason is that when the suction surface boundary layer encounters the inverse pressure gradient at the outlet, the C-type pressure distribution absorbs a part of low energy fluid in the boundary layer. It indicates that the C-type pressure distribution reduces the thickening effect of adverse pressure gradient on the boundary layer.

\subsection{Averaged TPC distribution along axial direction}

As shown in figure 6, for the three cascades channels, it is not obvious that the TPC increases in the scope of 0 $60 \%$ relative axial chord length, but dramatically increases from the $60 \%$ relative axial chord length to the blade trailing edge. The increasing of TPC is mainly induced by the passage vortex and the increasing of the boundary layer that is caused by the outlet diffusion section.

The TPC sequentially increases at the blade outlet because of the intense mixing airflow between the suction side airflow and the pressure side airflow at the outlet. Certainly, as shown in figure 3, we discovered that the static pressure isoline forms closed curve, which indicated that the outlet flow is three-dimensional, unordered and chaotic.

\section{Conclusion}

The numerical simulation of steam turbine nozzle cascades were carried out by using CFX, including the straight blade, the fore-swept blade and the aft-swept blade. The simulation results are given.

1. The fore-swept blade and the aft-swept blade along the spanwise developed the C-type and the reverse C-type static pressure distribution, respectively. On the one hand, the static pressure of fore-swept is smaller on both sides and higher at the middle than the prototype blade. On the other hand, the static pressure of aft-swept is higher on both sides and lower at the middle than the prototype blade. The $\mathrm{C}$-type static pressure distribution pushes the upper and lower passage vortices to the mainstream flow at the blade middle, and the passage vortices sucks and swirls the two sides' boundary layer, having low momentum airflow. The C-type pressure distribution decreases the total pressure loss on both sides of the cascades and increases the flow loss at the middle of spanwise. Contrast to the reverse C-type of static pressure distribution, the C-type pushes the upper and lower passage vortex to both sides.

2. Compare to the prototype blade, the fore-swept blade reduces the flow loses at the blade middle, increases the flow loss on both endwalls, and makes the endwalls flow deterioration. The aft-swept blade increases the flow loses at the blade middle and decreases the flow loss at the both up and down endwalls.

3. Aft-swept blade decreases the total pressure loss, and also makes the outlet aerodynamic parameters evenly distributed along blade height. The aft-swept blade's aerodynamic performance is better than the fore-swept blade and the straight blade.

\section{Acknowledgements}

Natural Science Foundation of China (No. 51774091; No. 51607035) and Heilongjiang Province Postgraduate Pedagogy Innovation Engineering Projects (No. JGXM_HLJ_2016043) have funded this research work.

\section{References}

[1] Simon J G and John J B 2002 The use of sweep and dihedral in multistage axial flow compressor blading: Part I-university research and methods development. J. Turbomach. 124(4): 521-532

[2] Denton L D and Xu L 2002 The effects of lean and sweep on transonic fan performance: a computational study. ASME Int. Gas Turbine Inst. Pub. IGTI 5A: 23-32

[3] Shan P and Liu X Y 2000 Analysis on the aerodynamic behaviors of the swept leading edge shocks in high load axial 
compressors. Acta Aeronautica et Astronautica Sinica 21(2): 97-102

[4] Sasaki T and Breugelmans F 1998 Comparison of sweep and dihedral effects on compressor cascade performance. $J$. Turbomach. 120(3): 454-464

[5] Zhou Z P, Zhao L D and Chen M Z 1998 Three-dimensional blading and its influence on blade aerodynamic loading. $J$. Aerosp. Power. 13(3): 235-240

[6] Corsini A and Rispoli F 2003 The role of forward sweep in subsonic axial fan rotor aerodynamics at design and off-design operating conditions. ASME Int. Gas Turbine Inst. Pub. IGTI 6A: 543-553

[7] Neubert R J, Gendrich C P 2003 HSCT forward swept fan performance. ASME Int. Gas Turbine Inst. Pub. IGTI 6A: 625-631

[8] Yang A L and Chen K M 2000 Effects of the axial swept blade on aerodynamice-aeroacoustic performances of the turbine stator flow. Fluid Mach. 29(3): 25-28

[9] Launder B and Spalding D 1972 Lectures in mathematical models of turbulence. London: Academic press 